\title{
A Survey of Cultured Penaeid Shrimp in Taiwan for Viral and Other Important Diseases
}

\author{
D. V. LightNeR ${ }^{* 1}$, R. P. HedRICK ${ }^{* 2,6}$, J. L. FRYER ${ }^{* 3}$, \\ S. N. CHEN ${ }^{* 4}$, I. C. LIAO ${ }^{* 5}$ and G. H. KOU ${ }^{* 4}$ \\ ${ }^{* 1}$ Environmental Research Laboratory, University of Arizona, 2601 \\ East Airport Drive, Tucson, Arizona 85706 U.S.A. \\ *2Department of Medicine, School of Veterinary Medicine, \\ University of California, Davis, California 95616 U.S.A. \\ ${ }^{*}{ }^{3}$ Department of Microbiology, Oregon State University, Corvallis, \\ Oregon 97331 U.S.A. \\ ${ }^{*}$ Department of Zoology, National Taiwan University, Taipei, Taiwan, R.O.C. \\ *5Tungkang Marine Laboratory, Tungkang, Pingtung, Taiwan, R.O.C.
}

(Received November 27, 1986)

\begin{abstract}
A survey of disease problems adversely affecting cultured shrimp at farms in Southern Taiwan was conducted in March of 1986. Farms selected for inclusion in the survey were experiencing a variety disease problems in their shrimp stocks, including mortality, poor growth, and reduced food conversion efficiency. Some apparently healthy cultured penaeid stocks were also sampled and examined for signs of subclinical disease. Most of the eight facilities surveyed cultured Penaeus monodon exclusively, although two also contained other species $(P$. penicillatus, $P$. vannamei, and $P$. semisulcatus). These were also sampled and examined. Important virus pathogens found during the survey included the $P$. monodon-type baculovirus (MBV) found in both $P$. monodon and $P$. semisulcatus, and infectious hypodermal and hematopoietic necrosis (IHHN) virus disease in $P$. vannamei. MBV was the most prevalent major pathogen encountered in the survey, and it was found in samples of $P$. monodon from seven of the eight locations surveyed and in the single sample of $P$. semisulcatus. These findings indicate that $\mathrm{MBV}$ is a common infectious agent in cultured stocks of these species in Taiwan.

The disease hemocytic enteritis (HE) was also commonly observed in shrimp from five of the eight locations surveyed. This may indicate that the disease, which may be caused by an enteric toxin produced by certain types of blue-green algae, is an important disease of cultured shrimp in Taiwan. Also found in the study were two idiopathic syndromes which often, but not always, occurred together in the same shrimp. The first of these syndromes was a generalized diffuse inflammatory disease (II), which was found in several populations of $P$. monodon and in two stocks of $P$. penicillatus. The other idiopathic condition, often was observed in shrimp with II, was characterized by hypertrophy of Oka's lymphoid organ, and disassociation and metastasis of spherical clumps of cells derived from the hypertrophied organ. A number of apparently ubiquitous penaeid epicommensals were observed on the gills, appendages, and general body surface of many shrimp sampled in the survey, and some were associated with disease and mortality.
\end{abstract}

Despite the rapid expansion of the culture of penaeid shrimp in Taiwan, relatively little is known about the prevalence of viral diseases in these populations. The major shrimp species cultured in Taiwan is Penaeus monodon, with several others contributing to the total production. The species cultured and the methods used have recently been reviewed by LIAO (1985) and CHIANG and LIAO (1985). Liao et al. (1977) and Liao et al. (1985) have also reviewed some of the major recognized diseases that have adversely affected Taiwan's shrimp culture industry.

Accompanying the growth of Taiwan's shrimp 
Table 1. List of farms surveyed, culture system type(s), and the species sampled and examined for major penaeid pathogens or disease syndromes

\begin{tabular}{cll}
\hline Farm & \multicolumn{1}{c}{ Species sampled } & \multicolumn{1}{c}{ Culture system type(s)* } \\
\hline 1 & P. monodon $(P$. mon $)$ & unknown \\
2 & $\begin{array}{l}\text { P. monodon } \\
\text { P. monodon } \\
\text { P. penicillatus }(P . \text { pen })\end{array}$ & hatchery and semi-intensive ponds \\
3 & $\begin{array}{l}\text { P. vannamei }(P \text {. van }) \\
\text { P. monodon }\end{array}$ & and intensive tank culture \\
& $\begin{array}{l}\text { P. monodon } \\
\text { P. monodon }\end{array}$ & unknown \\
4 & Pemi-intensive ponds \\
5 & P. semisulcatus $(P$. sem $)$ & semi-intensive ponds \\
6 & semi-intensive ponds \\
7 & unknown \\
\hline
\end{tabular}

* Farm type is listed as unknown when samples were obtained from farmers who delivered samples during the survey to Tunkang Marine Laboratory (TML), but whose farms were not visited.

culture industry has been the more frequent occurrence of serious epizootics of which many remain unexplained. Although the baculovirus disease MBV ( $P$. monodon-type baculovirus) was first recognized in postlarval $P$. monodon imported to North America from Taiwan (LightNer and REDMAN, 1981; LIGHTNER et al., 1983a) the significance of the virus in Taiwan has not been determined.

In this report we summarize the results of a survey of cultured shrimp for disease conducted in late March 1986. The major emphasis of the survey was to determine the presence and significance of viral infections in cultured shrimp at selected locations in southern Taiwan.

\section{Materials and Methods}

\section{Source of Shrimp}

Personnel at the Tungkang Marine Laboratory (TML) Tungkang, Taiwan, arranged for collections of cultured shrimp from nearby farms that had reported problems with their stocks (Table 1). These included samples of shrimp from populations that showed reduced growth and food conversion efficiency, lower than expected production rates, and above normal mortalities. Also included in the survey were several apparently healthy penaeid populations that were examined for subclinical virus infections and other diseases.

\section{Diagnostic Methods}

Wet mounts of excised gills and hepato- pancreata were prepared from selected shrimp and examined by bright-field microscopy. A dilute solution of malachite green $(0.1 \%$ weight/volume in water) was used to enhance contrast of the MBV occlusion bodies in wet mounts (LIGHTNER, 1983). Additional diagnostic procedures followed were by routine histopathology or transmission electron microscopy (Lightner et al., 1983a, 1983c; LigHTNER, 1985).

Fifteen 12 to $20 \mathrm{~g}$ juvenile $P$. monodon from location number 2 near Fangliao, displaying gross signs of a possible infectious disease similar to infections hypodermal and hematopoietic necrosis (IHHN), were frozen for a pathogen bioassay. Subsequently, these shrimp were partially thawed, homogenized and pooled in $2 \%$ sterile saline, repackaged in $1 \mathrm{~g}$ amounts in sterile plastic bags, and immediately refrozen until used in the bioassay. Details of the bioassay procedure for IHHNV (IHHN virus) using juvenile $P$. stylirostris as the indicator for the presence of virus have been previously described (LigHTNER et al., 1983b). In this bioassay, homogenized $P$. monodon were fed to replicate groups of 25 juvenile $P$. stylirostris every other day for 14 days in an enclosed recirculating aquarium system containing artificial sea water of $25 \mathrm{ppt}$ (Fritz Sea Salts, Fritz Chemical Co., Dallas, TX), that was maintained at $24 \pm 1^{\circ} \mathrm{C}$ by a room air conditioner. A second replicate group was fed only a normal pelleted feed and served as an unexposed control. Samples for histological examination for signs of IHHN or related diseases were taken at 14 and 
Table 2. Farms surveyed, species sampled, and major diseases and pathogens found.

\begin{tabular}{|c|c|c|c|c|c|c|c|c|c|}
\hline \multirow{2}{*}{ Farm } & \multirow{2}{*}{ Species } & \multirow{2}{*}{ State/size } & \multicolumn{6}{|c|}{ Number infected* } & \multirow{2}{*}{ No. exam. } \\
\hline & & & MBV & IHHN & HE & II & $\mathrm{OHM}$ & FOUL & \\
\hline 1 & P. mon & $0.15-1 \mathrm{~g}$ & 3 & 0 & 1 & 0 & 0 & 2 & 5 \\
\hline 2 & P. mon & $-12 \mathrm{~g}$ & 5 & 0 & 1 & 6 & 2 & 6 & 6 \\
\hline \multirow[t]{6}{*}{3} & P.pen & $3-5 \mathrm{~g}$ & 0 & 0 & 0 & 2 & 2 & 2 & 3 \\
\hline & $P . p e n$ & $-12 \mathrm{~g}$ & 0 & 0 & 1 & 0 & 3 & 0 & 3 \\
\hline & $P$. van & $5-50 \mathrm{mg}$ & 0 & 1 & 0 & 0 & 0 & 0 & 3 \\
\hline & $P$. van & $0.01 \mathrm{~g}$ & 0 & 3 & 0 & 0 & 0 & 0 & 3 \\
\hline & P. van & $-20 \mathrm{~g}$ & 0 & 2 & 0 & 0 & 0 & 1 & 2 \\
\hline & Palaem. & $0.1-1.0 \mathrm{~g}$ & 0 & 2 & 0 & 0 & 0 & 0 & 6 \\
\hline 4 & $P$. mon & $0.1 \mathrm{~g}$ & 2 & 0 & 0 & 0 & 0 & 1 & 3 \\
\hline \multirow[t]{2}{*}{5} & P. mon & mysis & 0 & na & na & na & na & 0 & 8 \\
\hline & P. mon & $1-2 \mathrm{mg}$ & 3 & 0 & na & na & na & 0 & 7 \\
\hline 6 & P. mon & $2-3 \mathrm{~g}$ & 4 & 0 & 1 & 2 & 0 & 1 & 4 \\
\hline \multirow[t]{3}{*}{7} & P. mon & $1-4 \mathrm{~g}$ & 5 & 0 & 0 & 2 & 2 & 0 & 5 \\
\hline & P. mon & $4-8 \mathrm{~g}$ & 3 & 0 & 2 & 3 & 3 & 0 & 3 \\
\hline & P. mon & $3-12 \mathrm{~g}$ & 3 & 0 & 1 & 1 & 0 & 3 & 5 \\
\hline 8 & $P$. sem & $1-200 \mathrm{mg}$ & 2 & 0 & 0 & 0 & 0 & 0 & 8 \\
\hline
\end{tabular}

* Definitions of abbreviated terms not defined in the text:

na = diagnostic procedures used were "not applicable" for diagnosis of indicated disease at the developmental stage of animals in sample.

Palaem.$=$ Palaemon japonicus, a grass shrimp.

FOUL $=$ surface fouling organisms.

21 days post-initiation of carcass feeding.

Tissues processed for histopathology were fixed in either Davidson's acetic acid, alcohol, formalin solution (HUMASON, 1967) or in 10\% buffered formalin, and for electron microscopy in $6 \%$ phosphate buffered glutaraldehyde (LIGHTNER et al., 1983c). Tissue processing, embedding, sectioning, and staining for light and electron microscopy followed routine procedures previously documented (LightNer et al., 1983a, 1983b).

\section{Results}

\section{Viral Diseases}

MBV infections were found in the hepatopancreas and midgut of cultured $P$. monodon from all six locations sampled. MBV infections were also found in two populations of postlarval $P$. semisulcatus examined (Table 2). Malachite green stained wet-mounts of the hepatopancreas of postlarvae and young juvenile shrimp provided accurate diagnoses of moderate and heavy MBV infections, but not of light infections. In this procedure, MBV occlusion bodies were distin- guished by their staining more intensely green with malachite green than did other spherical structures in the hepatopancreas (such as nuclei and lipid droplets). However, this technique was found to be less applicable to older pondreared juveniles in which the hepatopancreas also contained numerous lipid droplets.

The presence in wet-mounts or histological sections of single or multiple eosinophilic occlusion bodies within hypertrophied nuclei of hepatopancreatic and midgut epithelial cells was considered diagnostic for MBV disease (Fig. 1). Occlusion bodies were also frequently observed free in the lumens of hepatopancreatic tubules and in the midgut lumen, as a result of cytolysis of necrotic MBV-infected hepatopancreatic epithelial cells. These occlusion bodies were composed of crystalline arrays of viral proteins and contained numerous occluded virions (Figs. 1a, 1b). Free nonoccluded virions (Fig. 1c) were also abundant in the nucleus of infected cells, and occasionally in the cytoplasm of some cells with degrading nuclear membranes (Fig. 1b).

Infection by IHHNV was detected in three of three populations of $P$. vannamei being 
held in quarantine at farm number three (Tables 1, 2). Baculovirus penaei (BP), although expected to be present in these imported stocks, was not detected.

The diagnosis of IHHNV was demonstrated by the presence of eosinophilic intranuclear inclusion bodies (Cowdry Type A; In Davidson's AFA fixed tissues) in tissues of ectodermal and mesodermal origin. In the postlarval $P$. vannamei examined, these pathognomonic inclusion bodies were principally located in focal lesions present in the gills (Fig. 2a), the foregut cuticular epithelium and subcutis (Fig. 2b), in circulating hemocytes (Fig. 2c), in antennal gland epithelium, in the loose connective tissues of gnathothorax, and in the cuticular epidermis. In the subadult $P$. vannamei examined, inclusion bodies were confined to the ventral nerve cord (Fig. 2d).

Adult grass shrimp (tentatively identified as Palaemon japonicus) collected from the same tank as were the subadult $P$. vannamei were free of signs of infection by IHHNV. However, developing embryos present on the pleopods of the females did contain histopathologic lesions suggestive of IHHNV infection. Eosinophilic intranuclear inclusion bodies (Cowdry Type A) were present in some of the developing embryos, but they were not abundant (Fig. 2e).

\section{Other Lesions}

Hemocytic enterities (HE) was found in $P$. monodon from four farms and in $P$. penicillatus from one farm (Table 2). Lesions typical of HE (LightNer, 1983) were observed in the midgut and associated ceca, and consisted of a necrosis of gut mucosal epithelium accompanied by a marked hemocytic inflammatory response (Figs. $3 a, 3 b)$. Often these lesions were septic.

An idiopathic generalized inflammatory condition (II) was observed in two species of shrimp (P. monodon and P. penicillatus) four farms (Table 2). These lesions were found primarily in loose connective tissues lining the hemocoel spaces of the gills and the antennal gland labyrinth, the lumen of the antennal gland tubules, the heart lumen, and in focal lesions in the subcuticular connective tissues (Figs. 4a-d). Shrimp with these microscopic lesions had mottled cuticles, felt rough to the touch, and were heavily fouled by epicommensal bacteria and protozoa. No re- cognizable agents were directly associated with these lesions. A bioassay, using frozen carcasses of $\boldsymbol{P}$. monodon with the condition (collected from Farm 2; Tables 1, 2), failed to produce the disease (or any other abnormalities as determined by the absence of mortalities relative to the untreated control group and by histological examination) in eight and nine carcass-fed juvenile $P$. stylirostris sampled from days 14 and 28, respectively, of the bioassay.

"Oka organ" hypertrophy and metastasis $(\mathrm{OHM})$ was observed in two species ( $P$. monodon and $P$. penicillatus) from three farms (Table 2). This prominent paired lymphoid organ, is normally located just lateral to either side of the midsagittal plane, just anterior to the capsular surface of the hepatopancreas and ventral to the stomach, and in intimate contact with each of the two subgastric arteries. OKA (1969) described the normal histology of the organ, and on the basis of its structure and intimate contact with the subgastric arteries, concluded that the organ was lymphoid. In most of the shrimp sampled and examined histologically in this survey, the structure of this organ conformed to OKA's (1969) description. However, in some shrimp sampled, this lymphoid organ was found to be enormously hypertrophied (Fig. 5), and to consist of both normal appearing lymphoid cells comprising sheaths around a central artery or vessel, and extremely active spherical clumps or "spheroids" of hyperplastic cells in which a central vessel was absent (Figs. $5 \mathrm{a}, 5 \mathrm{~b})$. These "OKA organ" spheroids were found in some cases to be disassociating from the main body of the Oka organ and as metastatic ectopic foci in the loose connective tissues of the gills (Fig. 6a), gonads (Fig. 6b), in the heart (Fig. $6 \mathrm{c}$ ), the antennal gland (Fig. 6d), and muscle. Some metastatic foci were found to be present at sites as distant as the third abdominal segment (Fig. 6e). The presence of hyperplasia, the spheroids, and metastasis of the spheroids from this organ seemed, in the cases where they were observed, to correlate with the presence of chronic disease syndromes including the idiopathic syndrome II that was characterized by diffuse multifocal aggregations of hemocytic inflammatory cells (Table 2). This apparent association of chronic inflammatory conditions to the OHM syndrome suggests that OKA's lymphoid organ 
may respond to chronic inflammation by hyperplasia, disassociation, and metastasis of disassociated cells.

"Red disease", a serious idiopathic syndrome of cultured $P$. monodon in Taiwan, was not observed in this study, possibly due its seasonal nature (LiAO et al., 1977, 1985).

\section{Surface Fouling Organisms}

The surface fouling organisms commonly observed included the filamentous bacterium Leucothrix mucor; the suctorian Acineta sp.; the stalked peritrichous ciliates Zoothamnium sp., Epistylis sp., and Vorticella sp.; and a small flagellate (Fig. 7) possibly belonging to the genus Bodo (Table 2). In certain instances, the presence of these organisms contributed to some of the problems reported by the shrimp farmers that participated in the survey.

\section{Discussion}

The commercial culture of penaeid shrimps has become a major component of Taiwan's economy, but few detailed surveys have been conducted that document the principle diseases affecting the industry. The existence of certain diseases, many of unknown etiology, have been recognized in these populations (LIAO et al., 1977, 1985), yet others present may not have been described. The purpose of this study was to examine certain of these diseases to determine their possible causes and the distribution of the agents involved. Eight farms in Taiwan rearing three species of penaeid shrimp were examined in March of 1986, and the presence of two viral diseases was established. Furthermore, an idiopathic inflammatory disease syndrome (II) described here for the first time, was found to be prevalent and may have a bacterial or viral etiology.

The first report of MBV was in $P$. monodon derived from Taiwan (LightNer and REDMAN, 1981), yet until this study its presence in cultured populations in Taiwan had not been confirmed. MBV was found to be widely distributed among populations of shrimp from farms in southern Taiwan. Within in our limited survey MBV was often associated with farms reporting poor survival and growth, especially in the early juvenile stages. However, even at locations not reporting these problems, light to moderate infections were observed, confirming earlier opinions of LIGHTNER et al. (1983a) that $P$. monodon can tolerate low to moderate infections if other cultural conditions are optimal.

Control of MBV disease may depend upon the use of virus-free broodstock. Presently, most of the commercial culture of shrimp in Taiwan is dependent on captive-wild broodstock, and the prevalence of $\mathrm{MBV}$ infections in these populations is unknown. Therefore, determination of the prevalence and distribution in wild stocks utilized by Taiwan could provide the industry with virus-free broodstock and would be the first stage in a program designed to control and then eradicate the disease.

IHHN disease was detected in $P$. vannamei at one facility surveyed. The three affected populations had been imported from a commercial hatchery in Panama, and it was most likely the source of the virus (Table 2). Supporting this conclusion was the absence of IHHN infections among native penaeids cultured at the same farm. In contrast to IHHN virus infections in $P$. stylirostris, which are diagnosed by routine histopathologic techniques, those in $P$. vannamei are not readily diagnosed by these methods (LIGHTNER et al., 1983b; BeLL and LightNer, 1984). However, in this survey IHHN was readily diagnosed by histopathological methods among $5-100 \mathrm{mg}$ juveniles selected because they exhibited external signs of infection (empty gut and opacity of the tail muscle) and histopathological lesions characteristic of the disease. Apparently, IHHN was enhanced by the high density at which these stocks were being reared.

IHHN was also found in two subadult $P$. vannamei using histologic procedures, however, pathognomonic lesions of the disease were not numerous and were confined to foci in the ventral nerve cord (Fig. 2d). Developing embryos on grass shrimp present in the same rearing tank as the subadult $P$. vannamei (which were apparently chronically infected with IHHN virus), may have also been infected by the virus. Lesions similar to those observed in IHHN infections in penaeid shrimp were observed in obviously diseased embryos, while no signs of infection were noted in six of six adult grass shrimp examined. If this apparent IHHN infection in these grass shrimp is 
confirmed, it would imply that non-penaeids could serve as alternate or reservoir hosts for the virus, complicating measures aimed at controlling the disease.

Contrary to our expectations, the baculovirus BP (Baculovirus penaei) was not detected in any of the three populations of $P$. vannamei sampled. $\mathrm{BP}$ is among the most common diseases of cultured $P$. vannamei in Panama and adjacent areas of Central and South America. Acute and subacute infections by BP are easily diagnosed by the presence of prominent tetrahedral intranuclear occlusion bodies in epithelial cells of the hepatopancreas tubules and midgut, and, as is the case with $\mathrm{MBV}$ in $P$. monodon, the disease is most prevalent in the earlier life stages (LIGHTNER, 1985). Two of the three populations of $P$. vannamei sampled were young juveniles, which presumably should have shown definite signs of BP infection had they been infected by the virus.

Hemocytic enteritis (HE) was found to be an important disease in this survey. This syndrome has been reported to be experimentally induced by certain types of filamentous blue-green algae and it may be ubiquitous in cultured penaeids (Lightner, 1985). This disease is thought to be caused by shrimp ingesting certain types of typically benthic blue-green algae (and possibly other endotoxin-rich microbes). Thus, the disease may lend itself to management by culture system design and by careful regulation of the pond culture systems to favor phytoplankton.

An apparently undescribed disease referred to here as idiopathic inflammation or II, was found in several stocks of $P$. monodon and in $P$. penicillatus (Table 2). From our samples, we were unable to establish an etiology for the disease, but it may be due to an infectious agent (e.g. a bacterium or a virus), a hypothesis consistent with many of the clinical manifestations. However, inflammatory lesions also accompany numerous other shrimp diseases such as vibriosis, Fusarium sp. infections, aflatoxicosis, "red disease", and the ascorbic acid deficiency syndrome, "black death" (LightNer, 1985). BANG (1983) in his review of crustacean disease responses, noted that endotoxin from Gram negative bacteria, which account for most of the described bacterial diseases of shrimp and much of their microflora (LightNer, 1985), can cause hemocyte clotting in the hemocoel, even when present in minute quantities. Thus, establishment of the etiology and significance of this disease will require further study.

Also reported for the first time is the condition we have tentatively designated "OKA organ" hyperplasia and metastasis (OHM). This condition is of unknown etiology, but has been previously observed in a number of species of cultured penaeids in a variety of geographic locations*. This condition may be a specific type of inflammatory response, rather than a lesion due to infection by a specific pathogen.

Surface fouling organisms were present on many of the shrimp examined. With the exception of the Bodo-like flagellate, most of the organisms observed (Leucothrix mucor, the colonial peritrich Zoothamnium sp., and the suctorian Acineta sp.), are commonly present on shrimp cultured in Taiwan and have been previously reported from Taiwan (LiAo et al., 1977; LiAo et al., 1985).

\section{Acknowledgement}

This work was supported in part by the National Science Foundation through grant number INT-85 01905 and the National Science Council of the Republic of China.

\section{References}

BANG, F. B. (1983): Crustacean disease responses. 113-153. In: A. J. A. J. Provenzano, Jr. (editor) The Biology of Crustacea. Vol. 6. Pathobiology, Academic Press, N. Y.

Bell, T. A. and D. V. Lightner (1984): IHHN virus: infectivity and pathogenicity studies in Penaeus stylirostris and Penaeus vannamei. Aquaculture, 38, 185-194.

ChIANG, P. and I. C. Liao (1985): The practice of grass prawn (Penaeus monodon) culture in Taiwan from 1968 to 1984 . J. World Aquaculture Soc., 16, 297-315.

Humason, G. L. (1967): Animal Tissue Techniques. W. H. Freeman and Co., San Francisco, CA. 432 pp.

LIAO, I. C., F. R. YANG, and S. W. Lou (1977): Preliminary report on some diseases of cultured prawn and their control methods. Reports on Fish Disease Research (I), JCRR Fisheries Series, N8. 29, 28-33.

LIAO, I. C. (1985): A brief review of the larval rearing

* LighTNER and Brock, unpublished data. 
techniques of penaeid prawns. 65-78. In: Y. Taki, J. H. Primavera and J. A. Llobera (editors), Proceedings of the First International Conference on the Culture of Penaeids Prawns/Shrimps. Aquaculture Department, Southeast Asian Fisheries Development Center, Iloilo, Philippines.

Liao, I. C., G. H. Kou, S. N. Chen, and J. Y. LaI (1985): Preliminary investigation on the diseases if cultured prawn in the Pingtung area. Fish Disease Research (VII) COA Fisheries Series No. 4.

Lightner, D. V. (1983): Diseases of Cultured Penaeid Shrimp. In: J. P. McVey (ed.), Handbook of Mariculture. Crustacean Aquaculture. Vol. 1: 289-320. CRC Press, Boca Raton, FL.

LightNer, D. V. (1985): A review of the diseases of cultured penaeid shrimps and prawns with emphasis on recent discoveries and developments. 79103. In: Proceedings of the First International Conference on the Culture of Penaeid Prawns/ Shrimps, Publ. by Aquaculture Dept. Southeast Asian Aquaculture Development Center, Iloilo,
Philippines.

Lightner, D. V. and R. M. REDman (1981): A baculovirus-caused disease of the penaeid shrimp, Penaeus monodon. J. Invertebr. Pathol., 38, 299-302.

Lightner, D. V., R. M. Redman, and T. A. Bell (1983a): Observations on the geographic distribution, pathogenesis and morphology of the baculovirus from Penaeus monodon Fabricius. Aquaculture, 32, 209-233.

Lightner, D. V., R. M. Redman, T. A. Bell, and J. A. Brock (1983b): Detection of IHHN virus in Penaeus stylirostris and $P$. vannamei imported into Hawaii. J. World Mariculture Soc., 14, 212-225.

Lightner, D. V., R. M. Redman, and T. A. Bell (1983c): Infectious hypodermal and hematopoietic necrosis (IHHN), a newly recognized virus disease of penaeid shrimp. J. Invertebr. Pathol., 42, 62-70.

OKA, M. (1969): Studies on Penaeus orientalis Kishinouye--VIII. Structure of the newly found lymphoid organ. Bull. Japan. Soc. Sci. Fish., 35, 245-250. 


\section{Figure Legends}

Fig. 1a. Light photomicrograph of a juvenile pond-reared Penaeus monodon with a moderate MBV infection of the hepatopancreas. Present in the tubule epithelium of adjacent tubules are hypertrophied MBV-infected nuclei with well developed spherical occlusion bodies (OB) and two other MBV-infected nuclei at an earlier stage of infection (E). H \& E. $(\times 675)$.

1b. Transmission electron micrograph of an MBV-infected hepatopancreatocyte. Virions of MBV (arrows) are present free in the nucleoplasm and embedded within the occlusion body (OB) matrix, and in the cytoplasm near a rupture in the nuclear membrane (small arrow). Occlusion body proteins (OP) have crystalized in the cytoplasm, but do not contain virions. $(\times 6800)$.

1c. A higher magnification TEM of several nonoccluded MBV virions. Spheres (arrow) arranged along the envelope of the center virion are polyhedrin (occlusion body) protein subunits. $(\times 27,000)$.

Fig. 2. Histological sections showing IHHN intranuclear eosinophilic inclusion bodies (arrowheads) in tissues of juvenile and subadult $P$. vannamei, and an IHHN-type inclusion body in a developing embryo of a grass shrimp (probably Palaemon japonicus). All $\mathrm{H} \& \mathrm{E}$ and $\times 1000$.

2a. In the gills of a juvenile $P$. vannamei;

2b. In the connective tissue of the stomach serosa of a juvenile $P$. vannamei;

2c. In a circulating hemocyte in a hemocoel sinus in the gills of a juvenile $P$. vannamei; and

2d. In the ventral nerve cord of a subadult $P$. vannamei.

2e. An IHHN-like eosinophilic intranuclear inclusion body in a developing embryo of a grass shrimp.

Fig. 3. Hemocytic enteritis (HE):

3a. Low magnification photomicrograph of HE lesions shown in a cross section of midgut in the third abdominal segment of a juvenile $P$. penicillatus. Inset of area in box shows necrosis of mucosal epithelium (E) and marked hemocytic $(H)$ infiltration to midgut lumen (L). H \& E. $(\times 165$; inset $\times 265)$.

3b. Midsagittal section of the fifth and sixth abdominal segments of a juvenile $P$. monodon with HE. Masses of hemocytes $(\mathrm{H})$ are present in the affected areas of the midgut (MG) mucosa at it junction (arrow) with the hindgut (HG) and the posterior midgut caecum (C). H \& E. $(\times 165)$.

Fig. 4. Idiopathic inflammation or II, which is characterized by hemocytic infiltration $(\mathrm{H})$ and aggregation without an apparent pathogen or other hemocyte attracting agent, are shown in the tissues of juvenile $P$. monodon. All $\mathrm{H} \& \mathrm{E}$ and $\times 525$.

4a. In a hemocoel channel at the junction of a primary and secondary gill rami;

4b. In the lumen of antennal gland tubules;

4c. In the heart lumen; and

4d. In loose connective tissues of the hemocoel ventral to the heart.

Fig. 5. Hyperplasia and disassociation of the "Oka lymphoid organ" (O). All H \& E.

5a. Low magnification micrograph of a midsaggital section of the gnathorax of a juvenile $P$. monodon. Shown is the main body of the Oka organ $(\mathrm{O}-1)$, which is hypertrophied to several times its normal size. A detached process of the organ $(\mathrm{O}-2)$ is present in the hemocoel amongst the adjacent tubules of the antennal gland labyrinth $(A)$. $(\times 66)$.

Inset of area in box shows both normal $(N)$ components of the organ, and several spheroids $(S)(\times 200)$.

5b. A similar section of the Oka organ to that shown in 5a., but from a juvenile $P$. penicillatus. The organ is enormously hypertrophied and is located adjacent to the anterior surface of the hepatopancreas (HP) and in contact with antennal gland tubules $(A)$. $(\times 66)$.

Inset of area in box shows normal structural units of the Oka organ, which are composed of a central vessel or artery (arrows) that are surrounded by a peri-arterial sheath of lymphoid cells. Also shown are a number of Oka organ spheroids (S) which are aggregates of disassociated cells that do not surround a central vessel. $(\times 200)$

Fig. 6. Dissemination of the Oka organ. Metastatic Oka organ spheroids (arrowheads) are shown in ectopic locations. All H \& E:

6a. In a hemolymph channel of the gills of a juveniles $P$. monodon. $(\times 265)$.

6b. In the hemocoel near the testis $(\mathrm{T})$ of a juvenile $P$. penicillatus. $(\times 525)$.

6c. Among cardiac muscle fibers (C) of the heart of a juvenile $P$. penicillatus. $(\times 525)$.

6d. In the hemocoel adjacent to tubules of the antennal gland (A). $(\times 265)$.

6e. In the hemocoel of the third abdominal segment of a juvenile $P$. penicillatus. $(\times 525)$.

Fig. 7. Histologic section of the gills of $P$. penicillatus showing a small flagellate (arrowheads), possibly belonging to the genus Bodo. The protozoans are attached to the cuticle in the crypts between the lamellae. $(\times 660)$. 


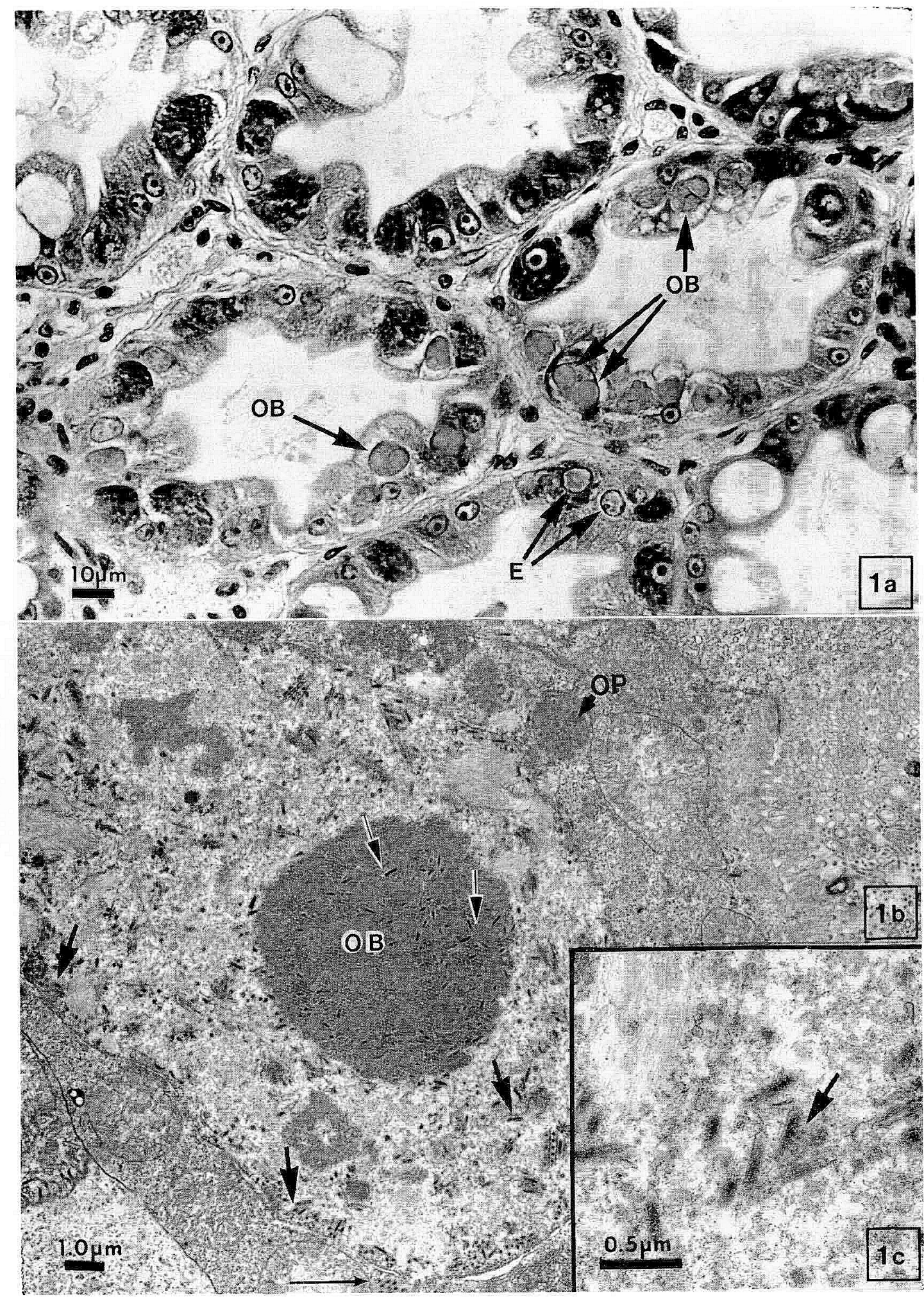




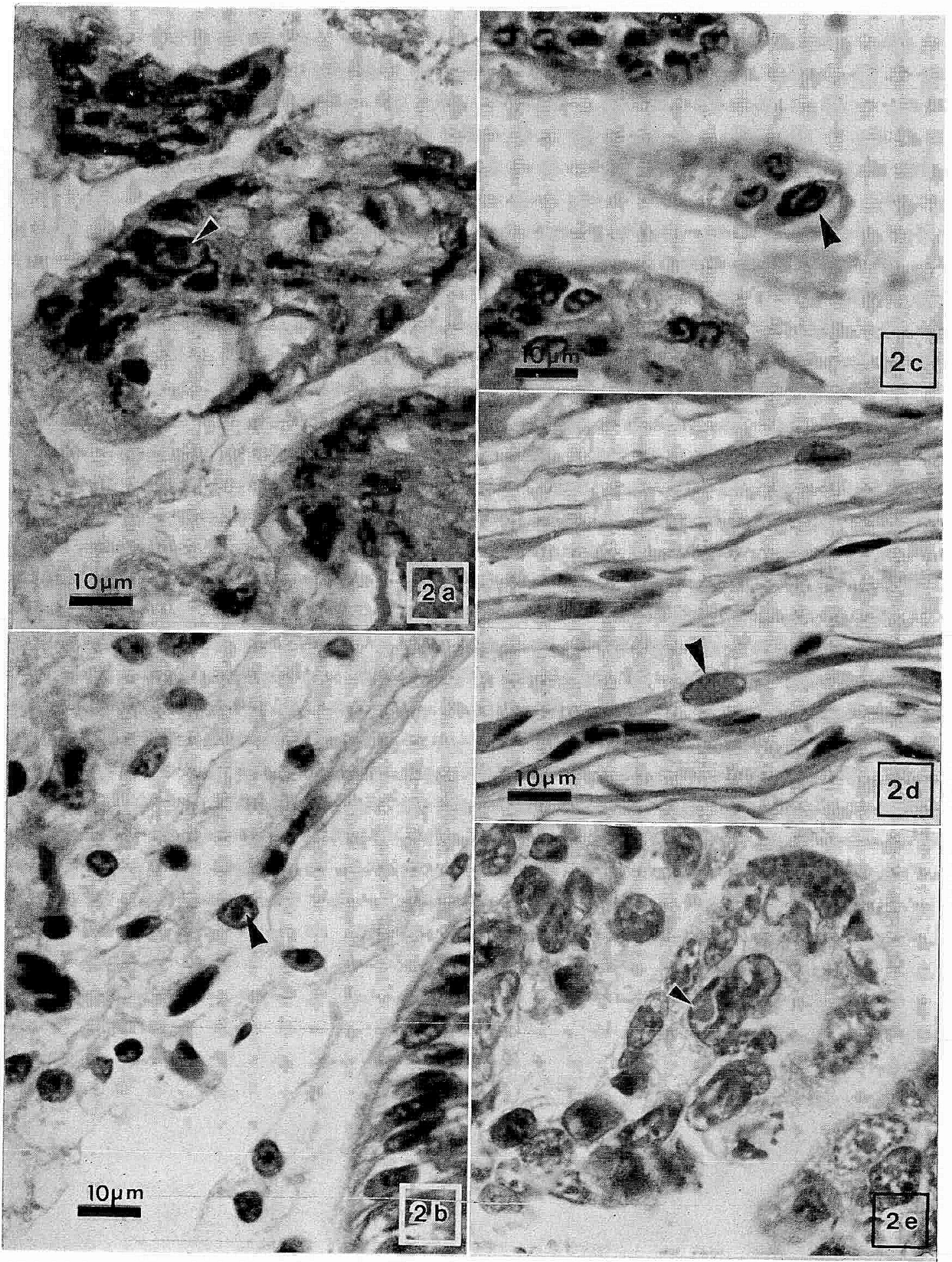




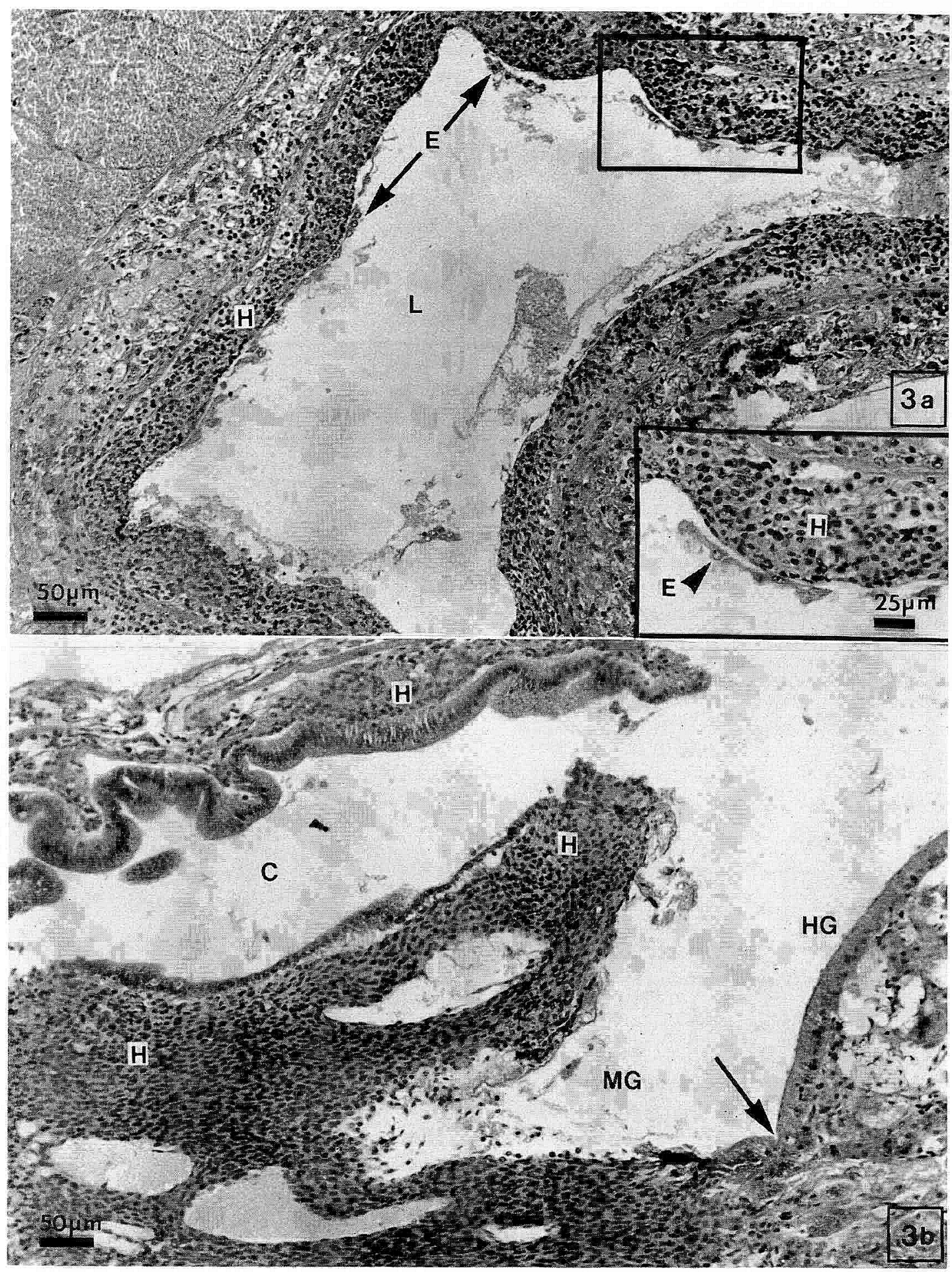




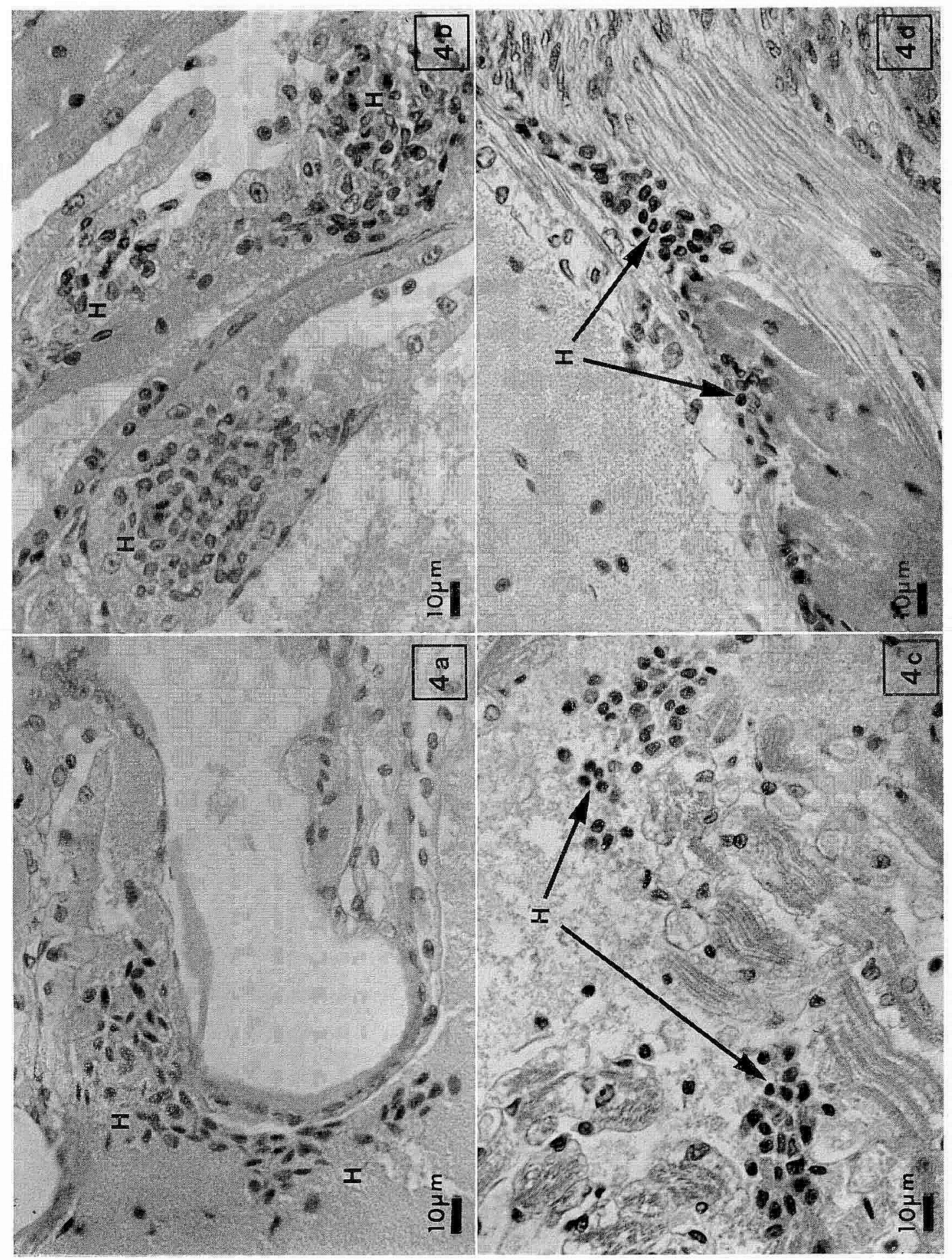




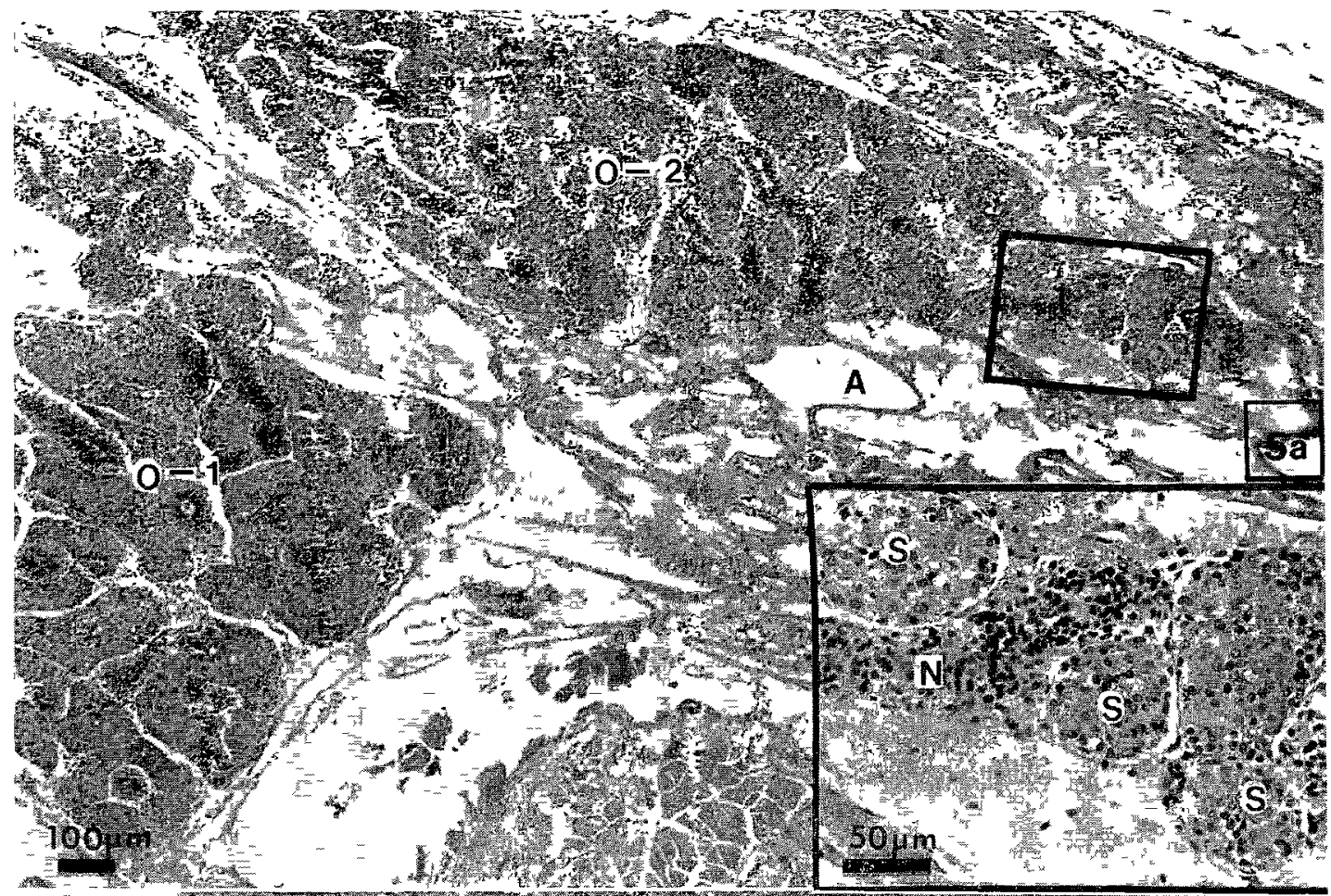

\section{A

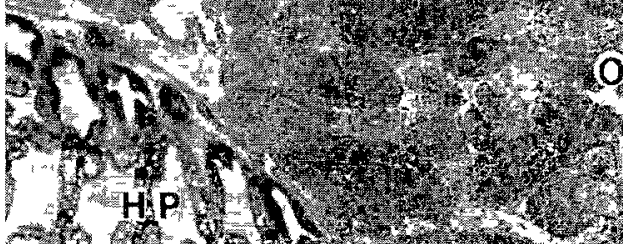 \\ स}

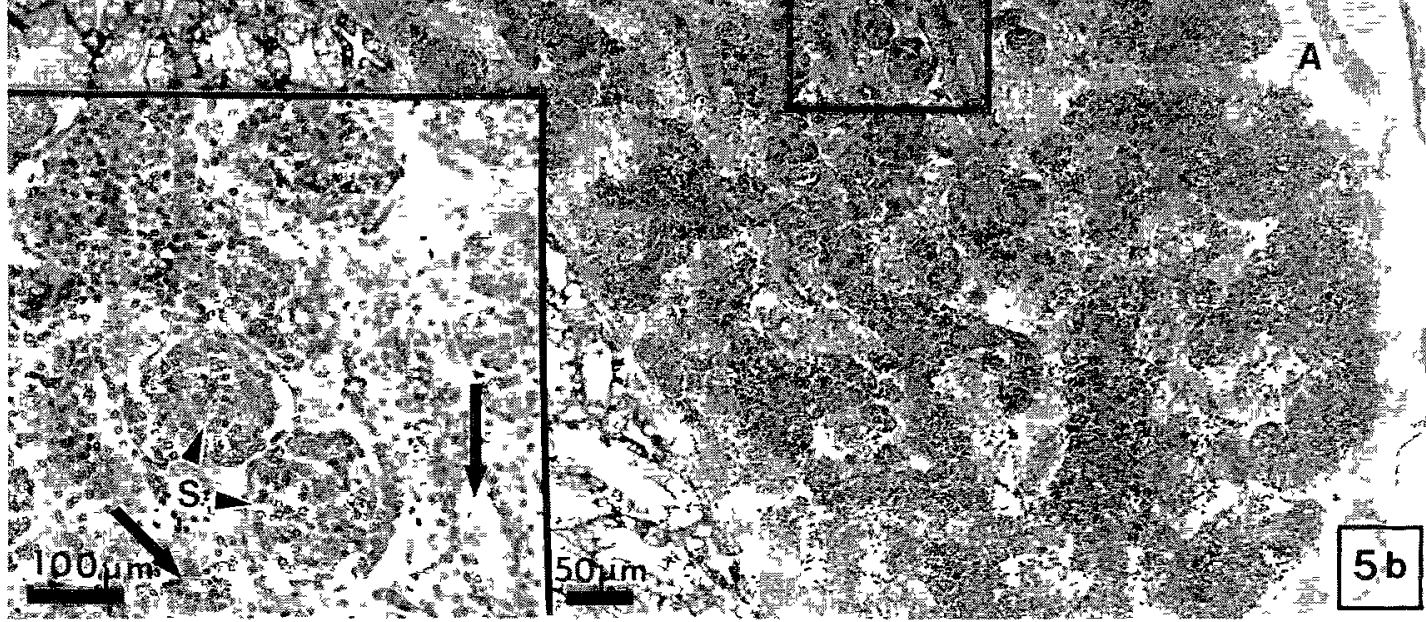




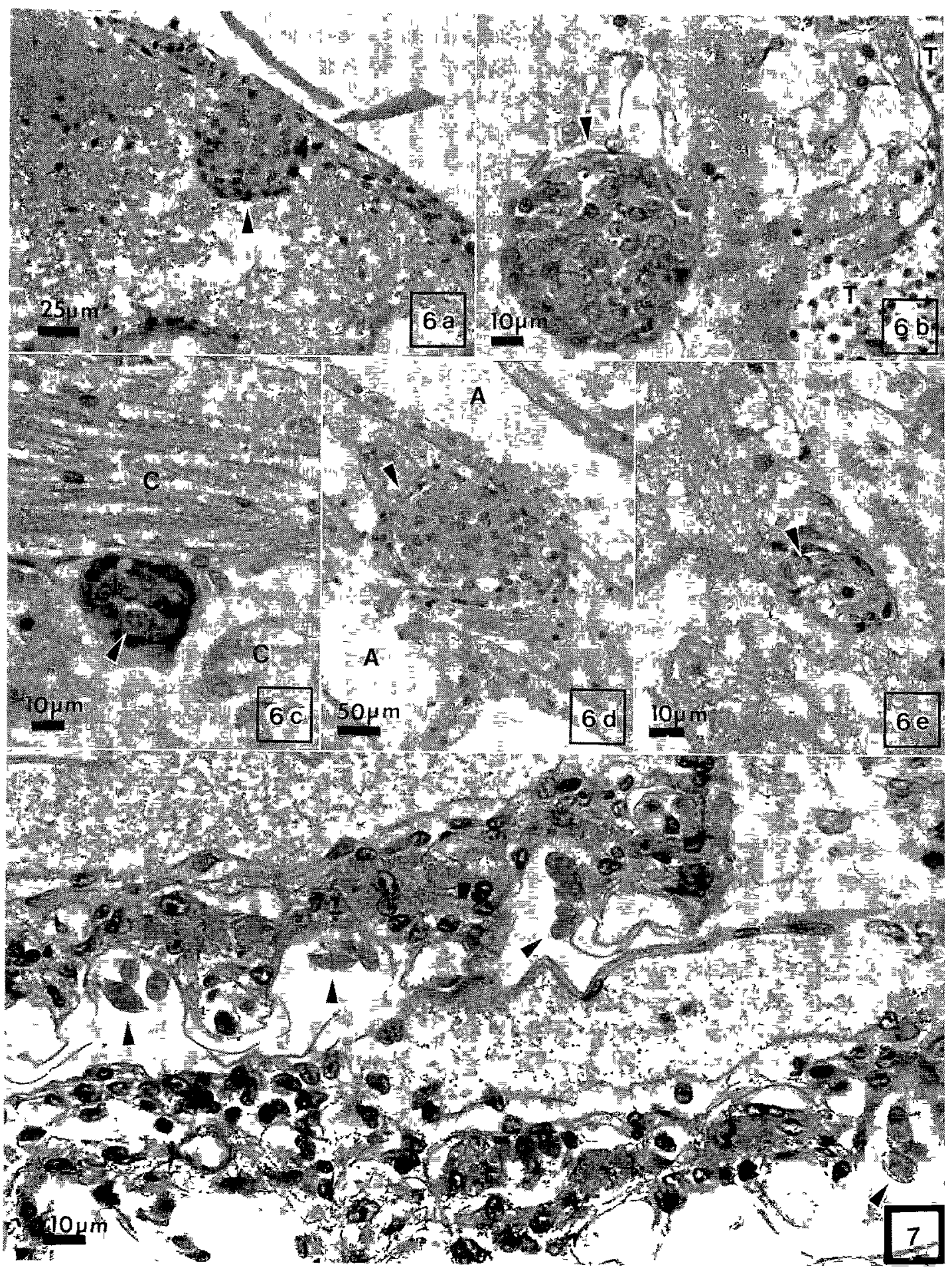

